\author{
Marquette University \\ e-Publications@Marquette
}

$1-2016$

\title{
An Empirical Examination of Symptom Substitution Associated with Behavior Therapy for Tourette's Disorder
}

\author{
Alan L. Peterson \\ University of Texas at San Antonio \\ Joseph F. McGuire \\ University of California, Los Angeles \\ Sabine Wilhelm \\ Harvard Medical School \\ John Piacentini \\ University of California, Los Angeles \\ Douglas W. Woods \\ Marquette University, douglas.woods@marquette.edu
}

See next page for additional authors

Follow this and additional works at: https://epublications.marquette.edu/psych_fac

Part of the Psychology Commons

\section{Recommended Citation}

Peterson, Alan L.; McGuire, Joseph F.; Wilhelm, Sabine; Piacentini, John; Woods, Douglas W.; Walkup, John T.; Hatch, John P.; Villarreal, Robert; and Scahill, Lawrence, "An Empirical Examination of Symptom Substitution Associated with Behavior Therapy for Tourette's Disorder" (2016). Psychology Faculty Research and Publications. 244.

https://epublications.marquette.edu/psych_fac/244 


\section{Authors}

Alan L. Peterson, Joseph F. McGuire, Sabine Wilhelm, John Piacentini, Douglas W. Woods, John T. Walkup, John P. Hatch, Robert Villarreal, and Lawrence Scahill 


\title{
An Empirical Examination of Symptom Substitution Associated With Behavior Therapy for Tourette's Disorder
}

\author{
Alan L. Peterson \\ University of Texas Health Science Center at San Antonio, South Texas Veterans Health \\ Care System, and University of Texas at San Antonio \\ Joseph F. McGuire \\ University of California, Los Angeles Semel Institute for Neuroscience \\ Sabine Wilhelm \\ Massachusetts General Hospital and Harvard Medical School \\ John Piacentini \\ University of California, Los Angeles Semel Institute for Neuroscience \\ Douglas W. Woods \\ Texas A\&M University \\ John T. Walkup \\ Weill Cornell Medical College \\ John P. Hatch \\ University of Texas Health Science Center at San Antonio \\ Robert Villarreal \\ University of Texas Health Science Center at San Antonio \\ Lawrence Scahill \\ Emory University School of Medicine
}

Behavior Therapy, Vol. 47, No. 1 (January 2016): pg. 29-41. DOI. This article is (C Elsevier and permission has been granted for this version to appear in e-Publications@Marquette. Elsevier does not grant permission for this article to be further copied/distributed or hosted elsewhere without the express permission from Elsevier. 
NOT THE PUBLISHED VERSION; this is the author's final, peer-reviewed manuscript. The published version may be accessed by following the link in the citation at the bottom of the page.

Abstract: Over the past six decades, behavior therapy has been a major contributor to the development of evidence-based psychotherapy treatments. However, a long-standing concern with behavior therapy among many nonbehavioral clinicians has been the potential risk for symptom substitution. Few studies have been conducted to evaluate symptom substitution in response to behavioral treatments, largely due to measurement and definitional challenges associated with treated psychiatric symptoms. Given the overt motor and vocal tics associated with Tourette's disorder, it presents an excellent opportunity to empirically evaluate the potential risk for symptom substitution associated with behavior therapy. The present study examined the possible presence of symptom substitution using four methods: (a) the onset of new tic symptoms, (b) the occurrence of adverse events, (c) change in tic medications, and (d) worsening of co-occurring psychiatric symptoms. Two hundred twenty-eight participants with Tourette's disorder or persistent motor or vocal tic disorders were randomly assigned to receive behavioral therapy or supportive therapy for tics. Both therapies consisted of eight sessions over 10 weeks. Results indicated that participants treated with behavior therapy were not more likely to have an onset of new tic symptoms, experience adverse events, increase tic medications, or have an exacerbation in co-occurring psychiatric symptoms relative to participants treated with supportive therapy. Further analysis suggested that the emergence of new tics was attributed with the normal waxing and waning nature of Tourette's disorder. Findings provide empirical support to counter the long-standing concern of symptom substitution in response to behavior therapy for individuals with Tourette's disorder.

Keywords: Tourette's disorder; chronic tic disorder; behavior therapy; symptom substitution; comprehensive behavioral intervention for tics

Over the past six decades, behavior therapy has been a major contributor to the development of evidence-based psychotherapy treatments (Antony \& Roemer, 2011). However, since the earliest emergence of behavior therapy, a long-standing concern among many psychodynamic and other nonbehavioral psychotherapists has been the potential risk for symptom substitution associated with behavior therapy (Kazdin, 1982; Nurnberger \& Hingtgen, 1973; Tryon, 2008). This concern about symptom substitution stems from the belief that behavior therapy is a superficial treatment that does not target the underlying causes of psychopathology such as unconscious internal conflicts ( $\underline{\text { Scahill et al., 2013 }}$ ). As a result, many nonbehavioral clinicians believe that focusing on overt, observable, or measureable behaviors - rather than the "underlying cause" - is not therapeutic and might even cause harm if the substituted symptom is worse than the targeted one (Kazdin, 1982). For instance, if behavior therapy was used to successfully treat one symptom of a particular disorder, there might be an increase in other symptoms of that disorder or a worsening of a comorbid symptom or condition.

One factor that has contributed to the continued belief in symptom substitution is that few studies have attempted to systematically evaluate its presence in response to behavioral interventions. This is largely attributed to the measurement and definitional challenges that complicate the investigation of symptom substitution (Kazdin, 1982; Tryon, 2008). First, symptoms that emerge or are "substituted" need to be differentiated from the

Behavior Therapy, Vol. 47, No. 1 (January 2016): pg. 29-41. DOI. This article is (C) Elsevier and permission has been granted for this version to appear in e-Publications@Marquette. Elsevier does not grant permission for this article to be further copied/distributed or hosted elsewhere without the express permission from Elsevier. 
targeted disorder prior to the initiation of behavior therapy. As many psychiatric problems include multiple distinct psychiatric symptoms, the clear identification of symptoms that are present at the onset of treatment is critical to clarifying which symptoms could be considered "new" or "substituted." Second, a temporal relationship between the original and substituted symptoms must be demonstrated with the new symptoms appearing within a specific window of time. While some suggest that the primary focus should be the time in which the patient is receiving behavior therapy (ryon, 2008), monitoring patients during a follow-up period after treatment can prove important as well (Kazdin, 1982). Finally, substituted symptoms have to be associated with the behavioral intervention beyond that of normal fluctuations of symptoms. While the internal nature of many psychiatric symptoms complicates these measurement and definitional challenges, psychiatric symptoms with overt behaviors present an ideal opportunity to empirically evaluate the potential risk of symptom substitution in response to behavior therapy. For instance, a recent randomized controlled trial (RCT) that compared psychoanalytic psychotherapy with cognitive-behavioral therapy (CBT) for bulimia nervosa found that CBT outperformed the psychoanalytic condition at the 2-year assessment point, with no evidence of symptom substitution (Hollon \& Wilson, 2014; Poulsen et al., 2014). The overt nature of motor and vocal tic symptoms associated with Tourette's disorder (TD) presents another opportunity to empirically assess the potential presence of symptom substitution in response to behavior therapy. Specifically, the natural occurrence of TD involves a waxing and waning of tics (Lin et al., 2002), with the onset of new tics not being uncommon. Therefore, the onset of new tic symptoms or worsening of tic severity that might be perceived as "evidence" of symptom substitution may result from the natural waxing and waning nature of tics.

Tics are sudden motor movements or vocalizations that begin in childhood and may persist into adulthood (Leckman, 2002). A persistent motor or vocal tic disorder (PTD; also known as chronic tic disorder) is defined by the presence of a single tic or multiple motor or vocal tics that persist for more than a year, with the diagnosis of Tourette's disorder (also known as Tourette syndrome) requiring both multiple motor tics and at least one vocal tic (not necessarily concurrently) that last more than a year (American Psychiatric Association, 2013). The prevalence of TD ranges from 0.4 to $1.6 \%$ (Knight et al., 2012; Scahill, Specht, \& Page, 2014). Common tics in children and adults with TD/PTD include eye blinking, head jerking, mouth movements, and simple vocalizations (McGuire et al., 2013). In community and clinical samples, TD/PTDs are associated with a wide range of behavioral and emotional difficulties (Conelea et al., 2011, 2013; Specht et al., 2011; Storch et al., 2007; Sukhodolsky et al., 2003). Thus, efficient and effective treatments are needed for individuals with TD/PTD.

Behavior Therapy, Vol. 47, No. 1 (January 2016): pg. 29-41. DOI. This article is (C) Elsevier and permission has been granted for this version to appear in e-Publications@Marquette. Elsevier does not grant permission for this article to be further copied/distributed or hosted elsewhere without the express permission from Elsevier. 
Pharmacological and behavioral interventions have demonstrated efficacy in the management of TD/PTDs. Although significantly reducing tic severity ( $\underline{\text { Singer, 2011), }}$ antipsychotics, atypical antipsychotics, and antihypertensives rarely eliminate tics and frequently produce unwanted side effects including sedation, weight gain, cognitive dulling, and other adverse effects that limit tolerability and medication adherence (Scahill et al., 2006). Meanwhile, behavior interventions have also demonstrated success in reducing tic severity (Peterson, 2007). These behavior therapy interventions include habit reversal training (HRT; Azrin \& Peterson, 1988, 1990; Peterson \& Azrin, 1992; Wilhelm et al., 2003) and the comprehensive behavioral intervention for tics (CBIT; Piacentini et al., 2010; Wilhelm et al., 2012; Woods et al., 2008). Notably, HRT serves as the principle therapeutic ingredient in CBIT, which incorporates functional assessment and function-based intervention procedures to mitigate influences of daily life that worsen tics. Despite the demonstrated efficacy of behavior therapy (McGuire et al., 2014), it is not widely used, in part due to misconceptions about the nature and treatment of tics that continue to persist among practitioners (Marcks, Woods, Teng, \& Twohig, 2004; Woods, Conelea, \& Walther, 2007). A common concern is that symptom substitution will occur with behavior therapy for tics, meaning that treatment of a given tic could result in the onset of new tic symptoms, an increase in severity of other tics, or the worsening of co-occurring psychiatric symptoms. For instance, if a head jerk tic improved or remitted with behavior therapy, the concern might be that the patient would develop a new "substituted" tic (e.g., arm twitch) in its place, and/or the patient would experience worsening of co-occurring psychopathology.

Although symptom substitution with behavior therapy has been a long-standing concern among nonbehavioral psychotherapists (Kazdin, 1982), there are only a few clinical anecdotes and uncontrolled case studies that provide support for this concept in TD/PTD (Burd \& Kerbeshian, 1987, 1988), with similarly minimal empirical evaluation to refute this claim. Woods, Twohig, Flessner, and Roloff (2003) provided preliminary data to challenge the notion of symptom substitution associated with behavior therapy. Woods and colleagues (2003) treated five children with multiple motor and vocal tics using HRT, but only targeted vocal tics. While vocal tics were reduced in four of the five children, the untreated motor tics did not increase and new tic symptoms were not reported to develop. Additionally, there was an $83 \%$ reduction in the targeted vocal tics and a $26 \%$ reduction in the untreated motor tics. These initial results suggest that behavior therapy may actually generalize to improvements in other nontreated symptoms, with no evidence of symptom substitution. Although noteworthy, this preliminary study was limited in sample size and scope of co-occurring psychiatric symptoms.

Behavior Therapy, Vol. 47, No. 1 (January 2016): pg. 29-41. DOI. This article is (C Elsevier and permission has been granted for this version to appear in e-Publications@Marquette. Elsevier does not grant permission for this article to be further copied/distributed or hosted elsewhere without the express permission from Elsevier. 
The present study empirically examined possible symptom substitution associated with behavior therapy using data combined from two previously published RCTs of children (Piacentini et al., 2010) and adults (Wilhelm et al., 2012). While the primary outcomes from these two RCTs demonstrated that participants receiving behavior therapy exhibited significant reductions in tic severity and had a greater treatment response than participants receiving supportive therapy, these two trials did not examine for the presence of symptom substitution. This secondary data analysis included 228 participants with TD/PTD from the previously published RCTs who had been randomly assigned to receive either behavior therapy or supportive therapy for the treatment of motor and vocal tics. Based on the measurement and definitional challenges noted above, the presence of symptom substitution was evaluated using four methods: (a) the emergence of new tic symptoms during treatment, (b) the occurrence of adverse events during treatment, (c) change in tic medications during treatment, and (d) worsening co-occurring symptoms after treatment. Furthermore, we explored factors that were associated with the onset of new tic symptoms across treatment conditions. Based on the findings of Woods and colleagues (2003), we hypothesized that behavior therapy would not be associated with the onset of new tics, the occurrence of adverse events, increase in tic medication, or worsening of co-occurring psychiatric symptoms relative to the supportive therapy condition.

\section{Materials and Methods}

\section{Participants}

The participants $(N=228)$ included 134 children and 94 adults with TD/PTD who were treated in two parallel RCTs examining the efficacy of a behavior therapy compared with a psychoeducation and supportive therapy (Piacentini et al., 2010; Wilhelm et al., 2012). An identical randomized two-group design was used for both the child and adult RCTs, and participants received eight sessions of behavior therapy or supportive therapy over a 10-week period. Primary assessments were conducted at the baseline, 5-week (midtreatment), and 10-week (posttreatment) assessment points, with a 6-month followup assessment completed by treatment responders. The participant demographic and clinical characteristics are presented in Table 1. With the noted exception of age, the two studies employed similar inclusion/exclusion criteria. Inclusion criteria included the following: (a) a TD/PTD of moderate or greater severity, (b) English fluency, (c) an estimated IQ $>80$, and (d) unmedicated or at least 6 weeks on stable dose of tic medications with no planned changes. Exclusion criteria included the following: (a) an

Behavior Therapy, Vol. 47, No. 1 (January 2016): pg. 29-41. DOI. This article is (C Elsevier and permission has been granted for this version to appear in e-Publications@Marquette. Elsevier does not grant permission for this article to be further copied/distributed or hosted elsewhere without the express permission from Elsevier. 
unstable medical condition; (b) current diagnosis of substance abuse/dependence; (c) lifetime diagnosis of pervasive developmental disorder, mania, or psychosis; and (d) four or more previous sessions of behavior therapy.

Table 1. Demographic and Clinical Characteristics of the Sample

$$
\text { Total sample }(N=228)
$$

\begin{tabular}{|c|c|c|c|c|c|}
\hline Characteristic & $N(\%)$ & & $n(\%)$ & $n(\%)$ & $\chi^{2}$ \\
\hline Male & $161(71 \%)$ & & $78(67 \%)$ & $83(74 \%)$ & 1.29 \\
\hline Adult & $94(41 \%)$ & & $50(43 \%)$ & $44(39 \%)$ & 0.34 \\
\hline Co-occurring OCD & $43(19 \%)$ & & $20(17 \%)$ & $23(21 \%)$ & 0.40 \\
\hline Co-occurring ADHD & $61(27 \%)$ & & $34(29 \%)$ & $27(24 \%)$ & 0.79 \\
\hline \multirow[t]{2}{*}{ Taking tic medication } & $72(32 \%)$ & & $38(33 \%)$ & $34(30 \%)$ & 0.15 \\
\hline & Mean $(S D)$ & Range & Mean $(S D)$ & Mean $(S D)$ & $t$ \\
\hline Age & $21.57(14.19)$ & $9-70$ & $22.05(14.18)$ & $21.06(14.25)$ & 0.53 \\
\hline Baseline YGTSS total tic score & $23.90(6.46)$ & $10-45$ & $24.41(6.48)$ & $23.38(6.43)$ & 1.20 \\
\hline Baseline YGTSS impairment score & $23.91(7.88)$ & $5-50$ & $24.09(8.20)$ & $23.72(7.56)$ & 0.35 \\
\hline Number of baseline tics on HM/VTS & $6.25(2.05)$ & $1-10$ & $6.33(2.01)$ & $6.16(2.10)$ & 0.6 \\
\hline
\end{tabular}

Note. CBIT $=$ comprehensive behavioral intervention for tics; PST $=$ psychoeducational and supportive therapy; $\mathrm{OCD}=$ obsessive-compulsive disorder; $\mathrm{ADHD}=$ attention deficit/hyperactivity disorder; YGTSS = Yale Global Tic Severity Scale; HM/VTS = Hopkins Motor/Vocal Tic Scale. ${ }^{*} p<.05$.

\section{Measures}

\section{Diagnostic Interviews}

Age-appropriate structured diagnostic interviews were used to assess tic and relevant co-occurring diagnoses at baseline. Given their common co-occurrence in the presentation of TD/PTD, relevant co-occurring diagnoses are obsessive-compulsive disorder (OCD) and attention deficit/hyperactivity disorder (ADHD). Child study participants were administered the child version of the Anxiety Disorders Interview Schedule (ADIS) for DSM-IV-TR ( Silverman \& Albano, 1996; Silverman, Saavedra, \& Pina, 2001; Wood, Piacentini, Bergman, McCracken, \& Barrios, 2002). Adult participants were administered the Structured Clinical Interview for DSM-IV (SCID; First, Spitzer, Gibbon, \& Williams, 2002).

\section{New Bothersome Tic Symptoms}

Participants identified up to five motor and five phonic tics deemed most bothersome at the baseline assessment using a modified version of the Hopkins

Behavior Therapy, Vol. 47, No. 1 (January 2016): pg. 29-41. DOI. This article is (C) Elsevier and permission has been granted for this version to appear in e-Publications@Marquette. Elsevier does not grant permission for this article to be further copied/distributed or hosted elsewhere without the express permission from Elsevier. 
Motor/Vocal Tic Scale (HM/VTS; Walkup, Rosenberg, Brown, \& Singer, 1992), which has demonstrated strong reliability and validity with other measures of tic severity. These tics were then rated on a 5-point scale that ranged from 0 (none) to 4 (severe) by an independent evaluator masked to treatment condition.

\section{Tic Severity}

Tic severity over the previous week was assessed using the Yale Global Tic Severity Scale (YGTSS; Leckman, Riddle, Hardin, \& Ort, 1989; Storch et al., 2005), a clinician-rated scale with demonstrated excellent reliability and validity. The YGTSS includes a symptom checklist of 40 commonly reported motor and vocal tics and yields four tic severity scores: total motor and total phonic score (range 0-25), total tic score (range 0-50), and impairment score (range 0-50). Tic severity on the YGTSS total tic score corresponds with the following definitions: minimal tics (1-9), mild tics (10-19), and moderate or greater tics ( $\geq 20$; Bloch \& Leckman, 2009).

\section{Global Improvement}

Primary treatment outcome regarding tic reductions was assessed using the Clinical Global Impression-Improvement Scale (CGI-I; Guy, 1976), a single-item clinician rating of overall change in clinical presentation from baseline. CGI-I scores range from 1 (very much improved) to 7 (very much worse). Ratings of very much improved and much improved were used to classify positive treatment response.

\section{Adverse Event Monitoring Form}

Adverse events were assessed prior to each therapy visit using a structured form with scripted questions that reviewed a wide array of current health concerns and medication use/changes (Piacentini et al., 2010; Wilhelm et al., 2012).

\section{Co-occurring Symptoms}

The most common co-occurring symptoms associated with TD/PTD were measured in both children and adult RCTs at baseline, posttreatment, and the 6-month follow-up assessment. This included ADHD, OCD, depression, and anxiety in both samples and oppositional defiant disorder behavior (ODD) in the child sample. As a result of ongoing data analyses, secondary outcomes on the adult CBIT study were unavailable, and only data on the child CBIT study are presented below. In the child RCT, ADHD was measured using the 18-item ADHD Rating Scale (ADHD-RS; DuPaul, Power, Anastopoulos, \& Reid, 1998).

Behavior Therapy, Vol. 47, No. 1 (January 2016): pg. 29-41. DOI. This article is (C) Elsevier and permission has been granted for this version to appear in e-Publications@Marquette. Elsevier does not grant permission for this article to be further copied/distributed or hosted elsewhere without the express permission from Elsevier. 
OCD symptoms were assessed using the 10-item Children's Yale-Brown Obsessive Compulsive Scale (CY-BOCS; Scahill et al., 1997). ODD behavior was measured with the eight-item Disruptive Behavior Rating Scale (DBRS; Barkley, 1997). Depression was assessed with the 27-item Children's Depression Inventory (CDI; Kovacs, 1992). Anxiety was measured with the Screen for Child Anxiety Related Emotional Disorders (SCARED; Birmaher et al., 1997).

\section{Treatment}

The behavior therapy treatment was the CBIT (Woods et al., 2008), which is an enhanced version of the behavior therapy treatment called habit reversal (Azrin \& Peterson, 1988, 1990; Peterson \& Azrin, 1992; Wilhelm et al., 2003). CBIT includes six primary components: awareness training, functional assessment and intervention, contingency management, relaxation training, competing response training, and generalization training (Woods et al., 2008). The primary component that targets tic reduction is the competing response procedure. Competing responses are behaviors that are incompatible with the tics, such as the isometric tensing of muscles opposite to the tic movements. Competing responses are designed to be able to be sustained for a brief period of time (e.g., at least 1 minute), to be inconspicuous, and to be compatible with ongoing activities. A tic hierarchy is developed, and then competing responses are implemented sequentially across treatment sessions starting with the most bothersome tic.

The psychoeducation and supportive therapy served as the comparison condition, and was designed to be similar to the standard supportive counseling that might be received in a community mental health clinic and to parallel the recommended adjunctive components of psychopharmacological treatment for individuals with TD/PTD ( Horn, 2005). It did not include any of the elements of behavior therapy, but offered educational information and support to help patients learn to better manage their tics. It provided disorder-specific information about the course, genetics, underlying neurobiology of TD/PTD, and the rationale for current treatments. Participants were permitted to discuss tics and related issues as part of supportive therapy, but therapists were instructed not to provide advice or specific interventions for tic management (Piacentini et al., 2010; Wilhelm et al., 2012).

\section{Procedures}

Procedures were reviewed and approved by the institutional review boards at each performance site, and all participants provided written informed consent (assent and

Behavior Therapy, Vol. 47, No. 1 (January 2016): pg. 29-41. DOI. This article is (C Elsevier and permission has been granted for this version to appear in e-Publications@Marquette. Elsevier does not grant permission for this article to be further copied/distributed or hosted elsewhere without the express permission from Elsevier. 
parental permission for minors). All procedures were performed in compliance with relevant laws and institutional guidelines in accordance with the ethical standards of the responsible committee on human experimentation (institutional and national) and with the Helsinki Declaration of 1975, as revised in 2000. Participants were recruited from six sites: Johns Hopkins School of Medicine; University of California, Los Angeles; University of Wisconsin-Milwaukee; Massachusetts General Hospital/Harvard Medical School; University of Texas Health Science Center at San Antonio; and Yale University. After consent and assent were obtained, participants completed a baseline assessment that included a structured diagnostic interview (ADIS or SCID), clinician-administered tic ratings (YGTSS, HM/VTS), and ratings of co-occurring psychopathology (ADHD-RS, CYBOCS, DBRS, CDI, SCARED). Clinical assessments were completed by an independent evaluator with a master's degree or higher in a mental health field and trained to reliability on the clinician-administered measures and received ongoing supervision (Piacentini et al., 2010; Wilhelm et al., 2012). Afterward, participants were randomly assigned to receive eight sessions of behavior therapy or supportive therapy over 10 weeks. Participants were reassessed by the independent evaluator who was blind to treatment condition at midtreatment (Week 5) and posttreatment (Week 10) on measures of tic symptoms (HM/VTS), tic severity (YGTSS), and treatment response (CGI-I). The independent evaluator specifically inquired about new bothersome tics that emerged after baseline at each subsequent assessment. If new bothersome tics were reported, they were documented and assessed for severity at the midtreatment and posttreatment assessments. Additional methodological details can be found in the previously published RCTs (Piacentini et al., 2010; Wilhelm et al., 2012).

\section{Analytic Plan}

Four procedures were used to examine possible symptom substitution. First, the onset of new tic symptoms was examined in response to the behavior therapy that specifically targeted the reduction of individual tics. The presence of symptom substitution would be evident if new tics were more likely to occur in the behavior therapy condition as compared with the supportive therapy condition. Second, the occurrence of adverse events was evaluated for both the behavior therapy and supportive therapy conditions. Symptom substitution would be observed if adverse events were more likely in the behavior therapy condition compared with supportive therapy. Third, changes in tic medications that occurred after the start of treatment were examined. Given that an increase in tic medication might serve as a proxy for worsening tic symptoms, symptom substitution would be observed if the behavior therapy condition had a greater frequency of tic medication changes relative to supportive therapy. Finally, worsening of nontargeted co-

Behavior Therapy, Vol. 47, No. 1 (January 2016): pg. 29-41. DOI. This article is (C Elsevier and permission has been granted for this version to appear in e-Publications@Marquette. Elsevier does not grant permission for this article to be further copied/distributed or hosted elsewhere without the express permission from Elsevier. 
occurring psychiatric symptoms was analyzed in the child RCT (Piacentini et al., 2010;

Woods et al., 2011). In this case, symptom substitution would be observed if participants in the behavior therapy condition experienced worsening of co-occurring psychiatric symptoms relative to the supportive therapy condition.

\section{Onset of New Tic Symptoms}

The first approach analyzed symptom substitution by examining the onset of new tic symptoms in response to either behavior therapy or improvement in individual tic symptoms targeted with behavior therapy. For this analysis, the HM/VTS ratings were reviewed and entered into a database. The YGTSS symptom checklist was then reviewed to determine and confirm the presence of new tics identified at midtreatment and posttreatment assessments. If the identified tic had been reported at a prior assessment on the YGTSS symptom checklist, it was assumed that the tic had increased in bothersomeness, but it was not classified as a new tic. If the tic was not endorsed previously on the YGTSS symptom checklist and was reported as a new tic on the HM/VTS, the tic was classified as a new tic. Similarly, the YGTSS symptom checklist was reviewed to determine the remission of bothersome tics identified at baseline. A tic was considered to be remitted if it had either a HM/VTS score of 0 or was no longer endorsed on the HM/VTS and the YGTSS symptom checklist. Of the original 248 participants, 20 had HM/VTS ratings that were considered to be unusable (e.g., illegible, inconsistent, or missing) and were excluded from analysis (8 CBIT, 12 PST). The remaining 228 participants were included in the analyses; 207 had complete data at all three assessments. There was no significant difference between the two treatment groups in terms of participants with incomplete data on the HM/VTS at all three assessments (7 CBIT, 14 PST, $\chi^{2}=2.85, p=.09$ ). Chi-square and independent sample $t$ tests compared baseline characteristics between treatment groups. Fisher's exact tests and independent sample $t$ tests assessed the relationship between treatment conditions related to the onset of any new bothersome tics on the HM/VTS. For those receiving behavior therapy, Fisher's exact test and Mann-Whitney procedures with exact significance test examined the relationship among the onset of any new bothersome tics, categorical reductions in tic severity (a reduction of 1 point or more for any tic on the HM/VTS), and tic remission (a zero severity rating for any tic on the HM/VTS) for any participants whose bothersome tics served as a treatment target. Across all participants, Fisher's exact tests and Mann-Whitney procedures with exact significance tests explored the relationship between the number of new bothersome tics and reductions in tic severity, tic remission, and treatment response. Given that this was the first large-scale systematic evaluation of symptom substitution in TD, all alternative hypotheses were two-sided, and statistical significance was set at the $p<.05$ level.

Behavior Therapy, Vol. 47, No. 1 (January 2016): pg. 29-41. DOI. This article is (C Elsevier and permission has been granted for this version to appear in e-Publications@Marquette. Elsevier does not grant permission for this article to be further copied/distributed or hosted elsewhere without the express permission from Elsevier. 
NOT THE PUBLISHED VERSION; this is the author's final, peer-reviewed manuscript. The published version may be accessed by following the link in the citation at the bottom of the page.

\section{Occurrence of Adverse Events}

The second approach to evaluating symptom substitution was to examine adverse events that may have occurred as a result of behavior therapy. The monitoring of adverse events was completed using methods similar to those used in biomedical clinical trials (Peterson, Roache, Raj, \& Young-McCaughan, for the STRONG STAR Consortium, 2013). At the start of every therapy session, therapists asked participants about possible adverse events (i.e., recent health complaints, behavioral changes, visits for medical/mental health care, changes in medications, and hospitalizations). Participants were also offered the opportunity to spontaneously report any other problem. Positive responses were documented regardless of whether they were thought to be related to the therapy. For each possible adverse event reported, additional details were gathered about the onset, severity, and outcome of the event, and measures taken to address it. An increase in tics was considered an adverse event when a participant or parent reported the worsening of a tic at the start of a treatment session when adverse events were assessed. Fisher's exact test compared the incidence of worsening tic symptoms between treatment conditions for each RCT.

\section{Change in Tic Medications}

The third approach to evaluating symptom substitution was to examine any change in tic medications that may have occurred as a result of the behavior therapy. Participants who were receiving psychotropic medications for tics or co-occurring psychiatric disorders were eligible to participate in both the child and adult RCTs if the dose was stable for 6 weeks and there were no planned changes during study participation. If a participant's tic symptoms drastically worsened, the participant's tic medication would likely have been changed in response. Fisher's exact test compared the incidence of tic medication changes between treatment conditions for each RCT.

\section{Worsening of Co-Occurring Psychiatric Symptoms}

The final approach to evaluating symptom substitution was to examine any changes in co-occurring psychiatric symptoms that may have occurred as a result of the treatment of the primary tic symptom. Changes in co-occurring psychiatric outcomes were measured for ADHD, OCD, ODD, depression, and anxiety. A complete description of the measures and statistical analyses are included in the original secondary outcomes manuscript for the child RCT (Woods et al., 2011). Given that similar analyses have not been completed for the adult RCT, evaluation of changes in co-occurring symptoms was limited to the child RCT.

Behavior Therapy, Vol. 47, No. 1 (January 2016): pg. 29-41. DOI. This article is (C Elsevier and permission has been granted for this version to appear in e-Publications@Marquette. Elsevier does not grant permission for this article to be further copied/distributed or hosted elsewhere without the express permission from Elsevier. 
NOT THE PUBLISHED VERSION; this is the author's final, peer-reviewed manuscript. The published version may be accessed by following the link in the citation at the bottom of the page.

\section{Results}

Participants included 228 children $(n=134)$ and adults $(n=94)$ with a primary diagnosis of TD/PTD. A total of 116 (51\%) received behavior therapy, and the remaining participants $(n=112,49 \%)$ received supportive therapy. Detailed participant characteristics are found in Table 1. There were no significant differences at baseline between treatment groups on demographic characteristics, tic severity, or the number of bothersome tics nominated at baseline. The primary outcomes regarding tic reductions in the original RCTs indicated that participants treated with CBIT were significantly more likely to be classified as treatment responders on the CGI-I (child $=53 \%$, adult $=38 \%$, combined sample $=45 \%$ ) as compared with those treated with the supportive therapy (child $=19 \%$, adult $=6 \%$, combined sample $=13 \%$; Piacentini et al., 2010; Wilhelm et al., 2012).

\section{Onset of New Tics in Relation to Treatment Condition}

Across both treatment conditions, participants exhibited an average of 1.25 new bothersome tics ( \pm 1.53 new tics) over the 10-week trial as measured by the HM/VTS. Fisher's exact test identified that the onset of a new tic during treatment did not differ between behavior therapy and supportive therapy (see Table 2). Furthermore, an independent sample $t$ test found no difference in the number of new tics that developed between behavior therapy and supportive therapy conditions (see Table 2). For a more detailed analysis, the relationship between specific outcomes for tics targeted by behavior therapy and new tic development was examined on the HM/VTS. Fisher's exact test revealed that the reduction or remission of any targeted tics was not associated with the onset of a new tic during behavior therapy (see Table 2). Furthermore, Mann-Whitney tests identified that neither a reduction or remission of any bothersome tic on the HM/VTS was associated with the number of new bothersome tics that developed over treatment with CBIT (see Table 2). This analysis was not conducted for the supportive therapy condition because it did not involve the specific targeting of individual tics as part of the treatment.

Table 2. Onset of New Tic Symptoms in Relation to Treatment Condition

$\begin{array}{cc}\text { CBIT } & \text { PST } \\ (n=116) & (n=112) \\ N(\%) & N(\%)\end{array}$

Onset of a new bothersome tic symptom

$72(62 \%) \quad 62(55 \%)$

Fisher's $\quad p=.35$ exact

Behavior Therapy, Vol. 47, No. 1 (January 2016): pg. 29-41. DOI. This article is (C Elsevier and permission has been granted for this version to appear in e-Publications@Marquette. Elsevier does not grant permission for this article to be further copied/distributed or hosted elsewhere without the express permission from Elsevier. 
NOT THE PUBLISHED VERSION; this is the author's final, peer-reviewed manuscript. The published version may be accessed by following the link in the citation at the bottom of the page.

$\begin{array}{cc}\text { CBIT } & \text { PST } \\ (n=116) & (n=112) \\ N(\%) & N(\%)\end{array}$

Targeted tic reduction in treatmenta and association with $100(90 \%) \quad$ N/A any new tic onset

Targeted tic remission in treatmenta and association 60 (54\%) N/A with any new tic onset

Targeted tic reduction in treatmenta and association with $100(90 \%)$ N/A the number of new bothersome tics

Targeted tic remission in treatmenta and association with the number of new bothersome tics

$60(54 \%) \quad$ N/A

Mean $(S D) \quad$ Mean $(S D)$

Number of new bothersome tics
Fisher's $\quad p=.74$ exact

Fisher's $\quad p=.43$ exact

$z=-1.15 \quad .25$

$z=-1.03 \quad .31$

$t_{226}=-\quad p=.97$

0.04 ,

Note . $\mathrm{CBIT}=$ comprehensive behavioral intervention for tics; $\mathrm{PST}=$ psychoeducational and supportive therapy; N/A = not applicable; $S D=$ standard deviation.

a111 participants in CBIT condition had tics nominated on Hopkins Motor/Vocal Tic Scale that were targeted in treatment.

\section{Association of New Tic Onset with Severity Reductions, Remission, and Clinical Response}

Given that there was no difference in the onset of new tic symptoms between treatment conditions, subsequent analyses explored whether the full remission of a tic or a reduction in the severity of any tic (targeted and nontargeted) on the HM/VTS was associated with new tic incidence across treatment conditions $(N=228)$. A Fisher's exact test identified that only the full remission of a bothersome tic (whether targeted by treatment or not) prior to midtreatment (Week 5) was associated with the onset of a new bothersome tic during that same 5 -week interval (Fisher's exact test, $p=.04$ ). Among the 134 participants who experienced the remission of a tic before Week 5, 68 participants (51\%) reported the onset of a new bothersome tic. Among 87 participants who did not experience the remission of a bothersome tic over this interval, 31 (36\%) participants reported the onset of a new bothersome tic. Meanwhile, a reduction in the severity (but not full remission) of any bothersome tic was not associated with the onset of a new bothersome tic during the first half of treatment (Fisher's exact test, $p=.81$ ). In addition, Fisher's exact tests identified that neither a decrease in severity $(p=.78)$ nor full remission $(p=.28)$ of any bothersome tics during the initial 5 weeks of treatment was associated with the onset of a new bothersome tic during the latter half of treatment. Furthermore, a reduction in tic severity (Fisher's exact test, $p=1.00$ ) and full remission (Fisher's exact test, $p=.26$ ) of any bothersome tic during the second 5 weeks of therapy

Behavior Therapy, Vol. 47, No. 1 (January 2016): pg. 29-41. DOI. This article is (C) Elsevier and permission has been granted for this version to appear in e-Publications@Marquette. Elsevier does not grant permission for this article to be further copied/distributed or hosted elsewhere without the express permission from Elsevier. 
was not associated with the onset of a new bothersome tic during this time interval. For a dimensional perspective, Table 3 examines the number of new bothersome tics that developed over the 10 -week trial as a function of tic severity reduction, tic remission, and treatment response. Remission of any bothersome tic during the first or second half of treatment was associated with an average onset of two new bothersome tics. Participants not exhibiting tic remission at either interval had, on average, less than one new tic onset during the 10-week trial. Participants who experienced a reduction in the severity of any bothersome tic in the latter half of treatment had an average of 1.38 new bothersome tics develop. Those who did not experience a reduction in the same time window developed an average of 0.65 new bothersome tics. Treatment response on the CGI-I was not associated with the development of an increased number of new bothersome tics.

Table 3. Categorical Predictors of New Bothersome Tics Over 10-Week Therapy Period

\begin{tabular}{lcccccc}
\multicolumn{1}{c}{ Categorical predictor } & Yes & $\boldsymbol{M} \pm \boldsymbol{S D}$ & No & $\boldsymbol{M} \pm \boldsymbol{S D}$ & $\boldsymbol{z}$ & $\boldsymbol{p}$ \\
Decreased tic severity BL to W5 & 202 & $1.28 \pm 1.55$ & 20 & $0.95 \pm 1.47$ & -1.24 & .215 \\
Tic remission BL to W5 & 134 & $1.52 \pm 1.73$ & 87 & $0.84 \pm 1.11$ & -2.94 & .003 \\
Decreased tic severity W5 to W10 & 189 & $1.38 \pm 1.59$ & 20 & $0.65 \pm 0.93$ & -2.09 & .037 \\
Tic remission W5 to W10 & 144 & $1.54 \pm 1.66$ & 63 & $0.79 \pm 1.12$ & -3.44 & .001 \\
Decreased tic severity from BL to W10 & 213 & $1.30 \pm 1.55$ & 4 & $1.50 \pm 1.73$ & -0.31 & .756 \\
Tic remission from BL to W10 & 185 & $1.44 \pm 1.59$ & 31 & $0.52 \pm 0.96$ & -3.60 & $<.001$ \\
CGI-I treatment responder at W5 & 31 & $1.16 \pm 1.37$ & 196 & $1.28 \pm 1.56$ & -0.15 & .877 \\
CGI-I treatment responder at W10 & 71 & $1.13 \pm 1.27$ & 144 & $1.37 \pm 1.65$ & -0.53 & .594
\end{tabular}

Note. BL $=$ baseline; W5 = Week 5; W10 = Week 10; CGI-I = Clinical Global Impression-Improvement Scale.

\section{Occurrence of Adverse Events}

In the child RCT (Piacentini et al., 2010), 200 adverse events were reported during the 10-week trial (76 in the behavior therapy condition and 124 in the supportive therapy condition). Adverse events were categorized into 13 different symptom clusters (e.g., upper respiratory infection, headache, tic worsening). There were no statistically significant differences between conditions for 12 of the 13 symptom clusters (see Piacentini et al., 2010 for a detailed list of all adverse events). Although falls and athletic injuries occurred more often in the supportive therapy condition $(n=19)$ than in the behavior therapy condition ( $n=7, p=.02$, Fisher's exact test), there was no significant difference in tic worsening above and beyond usual fluctuations reported between the behavior therapy group $(n=1,2 \%)$ relative to supportive therapy $(n=4,6 \%, p=.37$, Fisher's exact test). In the adult RCT (Wilhelm et al., 2012), 224 adverse events were reported during the 10-week trial (92 in the behavior therapy condition and 102 in the

Behavior Therapy, Vol. 47, No. 1 (January 2016): pg. 29-41. DOI. This article is (C) Elsevier and permission has been granted for this version to appear in e-Publications@Marquette. Elsevier does not grant permission for this article to be further copied/distributed or hosted elsewhere without the express permission from Elsevier. 
supportive therapy condition). Adverse events that occurred with more than $5 \%$ of study participants in each group were then categorized into 12 different symptom clusters. There were no statistically significant differences between groups for 11 of the 12 symptom clusters (see Wilhelm et al., 2012 for a detailed list of all adverse events). Irritability occurred more often in the supportive therapy condition $(n=6)$ than in the behavior therapy condition ( $n=0, p=.01$, Fisher's exact test). Similar to the child RCT, tic worsening above and beyond usual fluctuations was reported by four participants (6\%) in the behavior therapy condition and four participants (7\%) in the supportive therapy group ( $p=.99$, Fisher's exact test).

\section{Changes in Tic Medications}

In the child RCT (Piacentini et al., 2010), 23 participants (38\%) in the behavior therapy group and 23 participants (35\%) in the supportive therapy group were taking tic medications at baseline. Two participants in the behavior therapy group (3\%) and four participants in the supportive therapy group (6\%) reported a change in their tic medication type or dose during acute treatment ( $p=.68$, Fisher's exact test). In the adult RCT (Wilhelm et al., 2012), 17 participants (27\%) in the behavior therapy group and 14 participants (24\%) in the supportive therapy group were taking tic medications at the start of the study. None of the participants in the behavior therapy group reported a change in their tic medication type or dose during the treatment and only one participant in the supportive therapy group reported a change in medication type or dose ( $p=.48$, Fisher's exact test).

\section{Worsening of Co-Occurring Psychiatric Symptoms}

The results of the analysis of the secondary outcomes at posttreatment and 6-month follow-up assessments indicated that there were no statistically significant differences between those participants treated with behavior therapy and supportive therapy in terms of changes in any of the co-occurring symptoms (Woods et al., 2011). At the posttreatment assessment point, the measures of ADHD, OCD, ODD, depression, and anxiety were all improved for both behavior therapy and supportive therapy, but there were no statistically significant differences between treatment conditions (Woods et al., 2011). At the 6-month follow-up assessment, responders to behavior therapy exhibited decreased anxiety, disruptive behavior, family strain, and improved social functioning (Woods et al., 2011).

Behavior Therapy, Vol. 47, No. 1 (January 2016): pg. 29-41. DOI. This article is (C) Elsevier and permission has been granted for this version to appear in e-Publications@Marquette. Elsevier does not grant permission for this article to be further copied/distributed or hosted elsewhere without the express permission from Elsevier. 
NOT THE PUBLISHED VERSION; this is the author's final, peer-reviewed manuscript. The published version may be accessed by following the link in the citation at the bottom of the page.

\section{Discussion}

This study examined the presence of symptom substitution in response to behavior therapy using the combined data from two published RCTs on the treatment of TD/PTD (Piacentini et al., 2010; Wilhelm et al., 2012). Possible symptom substitution was examined using the following four methods: (a) the onset of new tic symptoms, (b) the occurrence of adverse events, (c) changes in tic medications, and (d) worsening of co-occurring psychiatric symptoms. First, the results suggested that the onset of new tic symptoms during treatment did not significantly differ between behavior therapy and supportive therapy conditions. These findings are noteworthy considering that the participants receiving behavior therapy were more likely to be considered treatment responders on the CGI-I (45\% response rate) as compared with supportive therapy (13\% response rate; Piacentini et al., 2010; Wilhelm et al., 2012). Second, the examination of adverse events suggested that participants receiving behavior therapy were not more likely to experience a worsening of tic symptoms or other adverse events relative to supportive therapy. Conversely, there were more adverse events related to supportive therapy compared with behavior therapy, but in most cases the differences were not statistically significant. Third, the examination of tic medications found that there was no difference in tic medication changes between treatment conditions. Finally, the examination of secondary psychiatric outcomes in the child RCT highlighted overall improvements in nontargeted co-occurring symptoms related to both treatments at both posttreatment and follow-up assessments (Woods et al., 2011). This finding is consistent with the general findings from most behavior therapy treatments, namely that improvements in secondary symptoms are often found to correlate with improvements in the primary targeted symptoms (Antony \& Roemer, 2011). Taken together, these findings highlight that symptom substitution was not more likely to occur to participants receiving behavior therapy compared with supportive therapy across these four methods.

Given that the onset of new tic symptoms was not associated with treatment condition, we explored other factors to understand the origins of new bothersome tics in treatment. Across both treatment conditions, the onset of a new bothersome tic was associated with the full remission of a bothersome tic within the 10 -week treatment period. Specifically, the remission of a bothersome tic within the first 5 weeks of the treatment was associated with the onset of a new bothersome tic during this same time window across treatment conditions. Stated differently, if a bothersome tic remitted, then a new bothersome tic was more likely to develop during treatment. These findings suggest that the onset of new tics is not a consequence of behavior therapy, and is most likely associated

Behavior Therapy, Vol. 47, No. 1 (January 2016): pg. 29-41. DOI. This article is (C Elsevier and permission has been granted for this version to appear in e-Publications@Marquette. Elsevier does not grant permission for this article to be further copied/distributed or hosted elsewhere without the express permission from Elsevier. 
with the normal waxing and waning of TD/PTD as it occurred equally across treatment conditions (Lin et al., 2002). Indeed, participants typically reported the onset of one to two new bothersome tics over the 10 -week treatment period. In regard to treatment outcome, there was no association between treatment response on the CGI-I and either the onset of a new bothersome tic or the number of new bothersome tics. Stated differently, if participants responded to treatment in either group, they were at no greater risk of developing new bothersome tics compared with participants who did not respond to treatment. From a broad perspective, the development of occasional new tics during therapy should be seen as part of the natural waxing and waning of tics. The changing nature of tic symptoms may be attributed in part to premonitory urge presence, as tics without premonitory urges were more likely to remit compared with tics with a premonitory urge (McGuire et al., 2015). Moreover, the development of occasional new tics was not associated with negative treatment outcomes in either treatment condition, with no available evidence suggesting that new bothersome tics will respond less well to treatment. Indeed, emerging research has identified specific tic characteristics and individual tics may be better candidates for treatment behavior therapy (McGuire et al., 2015).

To the best of our knowledge, the present study is the largest to empirically examine possible symptom substitution associated with behavior therapy in TD/PTD. However, this study should be interpreted within the context of its limitations. First, the analysis included a combined data set from two previous studies of children and adults. The original studies were conducted separately because of the differences required in the assessment and treatment of these participant populations. Although the research design, methods, and primary outcomes were almost identical, slight differences between the studies may have added some unidentified or unspecified confounds. Second, no missing data imputation strategies were used. This impacted 21 participants who had missing data on the HM/VTS at either midtreatment or posttreatment. Although this may have influenced our ability to identify the presence/remission of tics, most participants (91\%) had complete data at all three assessment points. Moreover, there were no significant differences in missing data between treatment groups. Third, given the focus on concerns of symptom substitution in response to behavior therapy, some clinical and demographic characteristics were not examined and could possibly be associated with the development of new bothersome tics. Finally, it could be argued that the present study is not technically a true test of symptom substitution because that would have required the comparison of behavior therapy with psychoanalytic treatment rather than supportive therapy.

Behavior Therapy, Vol. 47, No. 1 (January 2016): pg. 29-41. DOI. This article is (C Elsevier and permission has been granted for this version to appear in e-Publications@Marquette. Elsevier does not grant permission for this article to be further copied/distributed or hosted elsewhere without the express permission from Elsevier. 
NOT THE PUBLISHED VERSION; this is the author's final, peer-reviewed manuscript. The published version may be accessed by following the link in the citation at the bottom of the page.

\section{Conclusions}

The present study evaluated a long-standing concern among many psychodynamic and other nonbehavioral psychotherapists related to the potential risk of symptom substitution associated with behavior therapy (Kazdin, 1982; Nurnberger \& Hingtgen, 1973; Tryon, 2008). Across the few prior studies of symptom substitution, there has been limited evidence supporting its existence among anxiety disorders, enuresis, conversion disorder, habit conditions, and bulimia nervosa (Fuchs, 1980; Hollon \& Wilson, 2014; Nurnberger \& Hingtgen, 1973; Poulsen et al., 2014; Speed, 1996; Wille, 1993; Wille \& Anveden, 1995). While there have been a few reports suggesting that what was perceived as symptom substitution, a closer review suggests that it was more consistent with spontaneous recovery, relapse, or an extinction burst following discontinuation of behavior therapy (see Tryon, 2008). Although noteworthy, these prior examinations were mostly limited by small sample sizes and the methodological challenges associated with evaluating symptom substitution (Kazdin, 1982; Nurnberger \& Hingtgen, 1973; Tryon, 2008), with only one study using an RCT design (Hollon \& Wilson, 2014; Poulsen et al., 2014). Following design recommendations (Tryon, 2008), the present study compared two groups of demographically matched participants who received either behavior therapy targeted at reducing individual tics or psychoeducation and supportive therapy. In contrast to the concerns about the potential negative effects of behavior therapy, the results suggested that the positive benefits of behavior therapy generalized beyond the primary targeted behavior of tic reductions and also resulted in reductions in untreated comorbid symptoms at a 6-month follow-up assessment. Similarly, in contrast to the concerns of the possible detrimental effects of behavior therapy, there were fewer negative side effects with the CBIT intervention as compared with supportive therapy. While some methodological limitations and challenges exist in the present study, the results identify no difference in symptom substitution between behavior therapy and a nonbehavioral treatment.

For several decades, concerns regarding symptom substitution have served as barriers to the dissemination and implementation of behavior therapy for Tourette's disorder (Marcks et al., 2004; Scahill et al., 2013; Woods et al., 2007). Based on the results of the present study, future educational efforts should attempt to correct the misconceptions about behavior therapy among mental health clinicians, medical providers, patients, and families ( $\underline{\text { Scahill et al., 2013) }}$. Similar concerns have undoubtedly been expressed about behavior therapy as applied to other conditions. While this study adds to the growing evidence base against symptom substitution (Hollon \& Wilson, 2014; Poulsen

Behavior Therapy, Vol. 47, No. 1 (January 2016): pg. 29-41. DOI. This article is (C Elsevier and permission has been granted for this version to appear in e-Publications@Marquette. Elsevier does not grant permission for this article to be further copied/distributed or hosted elsewhere without the express permission from Elsevier. 
NOT THE PUBLISHED VERSION; this is the author's final, peer-reviewed manuscript. The published version may be accessed by following the link in the citation at the bottom of the page.

et al., 2014), additional research is needed to evaluate the potential risks and benefits of behavior therapy for other disorders. Such efforts may help to further reduce the barriers to care and enhance the public health impact of behavior therapy.

\section{Conflict of Interest Statement}

Drs. Peterson, Wilhelm, Piacentini, Woods, Walkup, and Scahill report receiving royalties from Oxford University Press for treatment manuals on tic disorders. Drs. Peterson, Wilhelm, Piacentini, Woods, Walkup, and Scahill report receiving honoraria for continuing education presentations from the Tourette Syndrome Association. Drs. Piacentini, Woods, and Walkup receive royalties from Guilford Press for a book on Tourette's disorder. Dr. Wilhelm reports receiving support in the form of free medication and matching placebo from Forest Laboratories for clinical trials funded by the National Institutes of Health (NIH) and receiving royalties from Guilford Publications, Springer, John Wiley, New Harbinger Publications, and Oxford University Press. She received research funding from the International Obsessive Compulsive Disorder Foundation, Novartis, and the Tourette's Syndrome Association, as well as consulting funds from the Mayo Foundation for Medical Education and Research. Dr. Piacentini also reports receiving support for his work from NIMH, Pfizer, and the Pettit Family Foundation and speaking honoraria from the International OCD Foundation. Dr. Woods reports receiving book royalties from New Harbinger and Springer Publications. Dr. Scahill has received royalties from Oxford University Press and American Psychiatric Press; has served as a consultant for Boehringer-Ingelheim, NeuroSearch, and Pfizer; and has had research support from Shire Pharmaceutical and Seaside Therapeutics. He also reports receiving support in the form of free medication and matching placebo from Shire Pharmaceuticals for a clinical trial funded by NIMH. Dr. Walkup reports receiving consulting fees from Eli Lilly and JAZZ Pharmaceuticals and lecture fees from CMP Media, Medical Education Reviews, McMahon Group, DiMedix, and the Tourette Disorder Association. He reports receiving free drug and matching placebo from Pfizer and Lilly and free drugs from Abbott for NIMH-funded clinical trials. He reports receiving fees for consultation with defense counsel and submission of written reports in litigation involving GlaxoSmithKline.

\section{Author Contributions}

Dr. Peterson, Dr. Hatch, Mr. McGuire, and Mr. Villarreal had full access to the data in the study and take responsibility for the integrity of the data and the accuracy of the data analysis; study concept and design: Drs. Peterson, Wilhelm, Piacentini, Woods, Walkup, and Scahill; analysis and interpretation of data: Dr. Peterson, Dr. Hatch, Mr. McGuire, and Mr. Villarreal; drafting of the manuscript: Dr. Peterson, Dr. Hatch, Mr. McGuire, and Mr. Villarreal; critical revision of the manuscript for important intellectual content: Drs. Peterson, Wilhelm, Piacentini, Woods, Walkup, and Scahill; statistical analysis: Dr. Hatch. Obtained funding: Drs. Peterson, Wilhelm, Piacentini, Woods, Walkup, and Scahill; administrative, technical, or material support: Dr. Peterson, Dr. Hatch, and Mr. McGuire; study supervision: Drs. Peterson, Wilhelm, Piacentini, Woods, Walkup, and Scahill.

Behavior Therapy, Vol. 47, No. 1 (January 2016): pg. 29-41. DOI. This article is (C) Elsevier and permission has been granted for this version to appear in e-Publications@Marquette. Elsevier does not grant permission for this article to be further copied/distributed or hosted elsewhere without the express permission from Elsevier. 


\section{Role of the Funding Source}

This research was supported by National Institute of Mental Health (NIMH) Grants R01MH070802 (Dr. Piacentini), R01MH069874 (Dr. Scahill), R01MH069875 (Dr. Peterson), and 5R01MH069877 (Dr. Wilhelm) from the NIMH with subcontracts to Drs. Walkup and Woods. The funding agency played no role in the study design; collection, analysis, or interpretation of data; the writing of this article; or the decision to submit the article for publication.

\section{Clinical Trial Registration}

clinicaltrials.gov, identifiers: NCT00218777 and NCT00231985.

\section{Previous Presentation}

Some results described in this paper were presented as a poster at the annual meeting of the Association for Behavioral and Cognitive Therapies, National Harbor, MD, on November 16, 2012.

\section{Acknowledgments}

We thank Julie Collins and Joel Williams for their role in providing editorial assistance in the preparation of this manuscript.

\section{References}

American Psychiatric Association, 2013 American Psychiatric Association Diagnostic and statistical manual of mental disorders (5th ed.), American Psychiatric Publishing, Washington, DC (2013)

Antony and Roemer, 2011 M.M. Antony, L. Roemer Behavior therapy American Psychological Association, Washington, DC (2011)

Azrin and Peterson, 1988 N.H. Azrin, A.L. Peterson Habit reversal for the treatment of Tourette syndrome Behaviour Research and Therapy, 26 (1988), pp. 347-351, 10.1016/0005-7967(88)90089-7

Azrin and Peterson, 1990 N.H. Azrin, A.L. Peterson Treatment of Tourette syndrome by habit reversal: A waiting-list control group comparison Behavior Therapy, 21 (1990), pp. 305-318, 10.1016/s0005-7894(05)80333-8

Barkley, 1997 R.A. Barkley Defiant children: A clinician's manual for assessment and parent training (2nd ed.), Guilford Press, New York, NY (1997)

Birmaher et al., 1997 B. Birmaher, S. Khetarpal, D. Brent, M. Cully, L. Balach, J. Kaufman, S.M. Neer The Screen for Child Anxiety Related Emotional Disorders (SCARED): Scale construction and psychometric characteristics Journal of the American Academy of Child and Adolescent Psychiatry, 36 (1997), pp. 545-553, 10.1097/00004583-199704000-00018

Bloch and Leckman, 2009 M.H. Bloch, J.F. Leckman Clinical course of Tourette syndrome Journal of Psychosomatic Research, 67 (2009), pp. 497-501, 10.1016/j.jpsychores.2009.09.002

Behavior Therapy, Vol. 47, No. 1 (January 2016): pg. 29-41. DOI. This article is (C) Elsevier and permission has been granted for this version to appear in e-Publications@Marquette. Elsevier does not grant permission for this article to be further copied/distributed or hosted elsewhere without the express permission from Elsevier. 
NOT THE PUBLISHED VERSION; this is the author's final, peer-reviewed manuscript. The published version may be accessed by following the link in the citation at the bottom of the page.

Burd and Kerbeshian, 1987 L. Burd, J. Kerbeshian Treatment-generated problems associated with behavior modification in Tourette disorder Developmental Medicine and Child Neurology, 29 (1987), pp. 831-833 Retrieved from http://onlinelibrary.wiley.com/journal/10.1111/\%28ISSN\%291469-8749

Burd and Kerbeshian, 1988 L. Burd, J. Kerbeshian Symptom substitution in Tourette disorder Lancet, 2 (1988), p. 1072, 10.1016/S0140-6736(88)90083-9

Conelea et al., 2011 C.A. Conelea, D.W. Woods, S.H. Zinner, C. Budman, T. Murphy, L.D. Scahill, ..., J. Walkup Exploring the impact of chronic tic disorders on youth: Results from the Tourette syndrome impact survey Child Psychiatry and Human Development, 42 (2011), pp. 219-242, 10.1007/s10578-010-0211-4

Conelea et al., 2013 C.A. Conelea, D.W. Woods, S.H. Zinner, C.L. Budman, T.K. Murphy, L.D. Scahill, ..., J.T. Walkup The impact of Tourette syndrome in adults: Results from the Tourette syndrome impact survey Community Mental Health Journal, 49 (2013), pp. 110-120, 10.1007/s10597-011-9465-y

DuPaul et al., 1998 G.J. DuPaul, T.J. Power, A.D. Anastopoulos, R. Reid ADHD Rating Scale-IV: Checklists, norms, and clinical interpretation Guilford Press, New York, NY (1998)

First et al., 2002 M.B. First, R.L. Spitzer, M. Gibbon, J. Williams Structured Clinical Interview for DSM-IVTR Axis I Disorders, Research Version, Patient Edition (SCID-I/P) Biometrics Research, New York State Psychiatric Institute, New York, NY (2002)

Fuchs, 1980 K. Fuchs Therapy of vaginismus by hypnotic desensitization American Journal of Obstetrics and Gynecology, 137 (1) (1980), pp. 1-7

Goetz and Horn, 2005 C. Goetz, S. Horn The treatment of tics R. Kurlan (Ed.), Handbook of Tourette's syndrome and related tic and behavioral disorders (2nd ed.), Dekker, New York, NY (2005), pp. 411-426

Guy, 1976 W. Guy Clinical global impressions W. Guy (Ed.), ECDEU assessment manual for psychopharmacology (Rev. ed., DHEW publication [ADM] 76-338), U.S. Department of Health, Education, and Welfare, National Institute of Mental Health, Rockville, MD (1976), pp. 217-222

Hollon and Wilson, 2014 S.D. Hollon, G.T. Wilson Psychoanalysis or cognitive-behavioral therapy for bulimia nervosa: The specificity of psychological treatments American Journal of Psychiatry, 171 (1) (2014), pp. 13-16, 10.1176/appi.ajp.2013.13101302

Kazdin, 1982 A.E. Kazdin Symptom substitution, generalization, and response covariation: Implications for psychotherapy outcome Psychological Bulletin, 91 (1982), pp. 349-365, 10.1037/0033$\underline{2909.91 .2 .349}$

Knight et al., 2012 T. Knight, T. Steeves, L. Day, M. Lowerison, N. Jette, T. Pringsheim Prevalence of tic disorders: A systematic review and meta-analysis Pediatric Neurology, 47 (2) (2012), pp. 77-90, 10.1016/j.pediatrneurol.2012.05.002

Kovacs, 1992 M. Kovacs Children's Depression Inventory manual Multi-Health Systems, North Tonawanda, NY (1992)

Leckman, 2002 J.F. Leckman Tourette's syndrome Lancet, 360 (2002), pp. 1577-1586, 10.1016/S01406736(02)11526-1

Leckman et al., 1989 J.F. Leckman, M.A. Riddle, M.T. Hardin, S.I. Ort The Yale Global Tic Severity Scale: Initial testing of a clinician-rated scale of tic severity Journal of the American Academy of Child and Adolescent Psychiatry, 28 (1989), pp. 566-573, 10.1097/00004583-198907000-00015

Behavior Therapy, Vol. 47, No. 1 (January 2016): pg. 29-41. DOI. This article is (C) Elsevier and permission has been granted for this version to appear in e-Publications@Marquette. Elsevier does not grant permission for this article to be further copied/distributed or hosted elsewhere without the express permission from Elsevier. 
NOT THE PUBLISHED VERSION; this is the author's final, peer-reviewed manuscript. The published version may be accessed by following the link in the citation at the bottom of the page.

Lin et al., 2002 H. Lin, C.B. Yeh, B.S. Peterson, L. Scahill, H. Grantz, D.B. Findley, ..., J.F. Leckman Assessment of symptom exacerbations in a longitudinal study of children with Tourette's syndrome or obsessive-compulsive disorder Journal of the American Academy of Child and Adolescent Psychiatry, 41 (2002), pp. 1070-1077, 10.1097/00004583-200209000-00007

Marcks et al., 2004 B.A. Marcks, D.W. Woods, E.J. Teng, M.P. Twohig What do those who know, know? Investigating providers' knowledge about Tourette's syndrome and its treatment Cognitive Behavioral Practice, 11 (2004), pp. 298-305, 10.1016/S1077-7229(04)80044-0

McGuire et al., 2013 J.F. McGuire, E. Nyirabahizi, K. Kircanski, J. Piacentini, A.L. Peterson, D.W. Woods, ..., L. Scahill A cluster analysis of tic symptoms in children and adults with Tourette syndrome: Clinical correlates and treatment outcome Psychiatry Research, 210 (2013), pp. 1198-1204, 10.1016/j.psychres.2013.09.021

McGuire et al., 2014 J.F. McGuire, J. Piacentini, E.A. Brennan, A.B. Lewin, T.K. Murphy, B.J. Small, E.A. Storch A meta-analysis of behavior therapy for Tourette syndrome Journal of Psychiatric Research, 50 (2014), pp. 106-112, 10.1016/j.jpsychires.2013.12.009

McGuire et al., 2015 J.F. McGuire, J. Piacentini, L. Scahill, D.W. Woods, R. Villarreal, S. Wilhelm, ..., A.L. Peterson Bothersome tics in patients with chronic tic disorders: Characteristics and individualized treatment response to behavior therapy Behaviour Research and Therapy, 70 (2015), pp. 56-63, 10.1016/i.brat.2015.05.006

Nurnberger and Hingtgen, 1973 J.I. Nurnberger, J.N. Hingtgen Is symptom substitution an important issue in behavior therapy? Biological Psychiatry, 7 (1973), pp. 221-236

Peterson, 2007 A.L. Peterson Psychosocial management of tics and intentional repetitive behaviors associated with Tourette syndrome D.W. Woods, J.C. Piacentini, J.T. Walkup (Eds.), Treating Tourette syndrome and tic disorders: A guide for practitioners, Guilford Press, New York, NY (2007), pp. 154-184

Peterson and Azrin, 1992 A.L. Peterson, N.H. Azrin An evaluation of behavioral treatments for Tourette syndrome Behaviour Research and Therapy, 30 (1992), pp. 167-174, 10.1016/00057967(92)90140-C

Peterson et al., 2013 A.L. Peterson, J.D. Roache, J. Raj, S. Young-McCaughan, STRONG STAR Consortium The need for expanded monitoring of adverse events in behavioral health clinical trials Contemporary Clinical Trials, 34 (2013), pp. 152-154, 10.1016/i.cct.2012.10.009

Piacentini et al., 2010 J. Piacentini, D.W. Woods, L. Scahill, S. Wilhelm, A.L. Peterson, S. Chang, ..., J.T. Walkup Behavior therapy for children with Tourette disorder: A randomized controlled trial Journal of the American Medical Association, 303 (2010), pp. 1929-1937, 10.1001/jama.2010.607

Poulsen et al., 2014 S. Poulsen, S. Lunn, S.I. Daniel, S. Folke, B.B. Mathiesen, H. Katznelson, C.G. Fairburn A randomized controlled trial of psychoanalytic psychotherapy or cognitive-behavioral therapy for bulimia nervosa American Journal of Psychiatry, 171 (2014), pp. 109-116, 10.1176/appi.ajp.2013.12121511

Scahill et al., 2006 L. Scahill, G. Erenberg, C.M. Berlin Jr., C. Budman, B.J. Coffey, J. Jankovic, ..., J. Walkup Contemporary assessment and pharmacotherapy of Tourette syndrome NeuroRx, 3 (2006), pp. 192-206, 10.1016/j.nurx.2006.01.009

Scahill et al., 1997 L. Scahill, M.A. Riddle, M. McSwiggin-Hardin, S.I. Ort, R.A. King, W.K. Goodman, ..., J.F. Leckman Children's Yale-Brown Obsessive Compulsive Scale: Reliability and validity Journal of

Behavior Therapy, Vol. 47, No. 1 (January 2016): pg. 29-41. DOI. This article is (C) Elsevier and permission has been granted for this version to appear in e-Publications@Marquette. Elsevier does not grant permission for this article to be further copied/distributed or hosted elsewhere without the express permission from Elsevier. 
NOT THE PUBLISHED VERSION; this is the author's final, peer-reviewed manuscript. The published version may be accessed by following the link in the citation at the bottom of the page.

the American Academy of Child and Adolescent Psychiatry, 36 (1997), pp. 844-852, 10.1097/00004583-199706000-00023

Scahill et al., 2014 L. Scahill, M. Specht, C. Page The prevalence of tic disorders and clinical characteristics in children Journal of Obsessive-Compulsive and Related Disorders, 3 (4) (2014), pp. 394-400, 10.1016/i.jocrd.2014.06.002

Scahill et al., 2013 L. Scahill, D.W. Woods, M.B. Himle, A.L. Peterson, S. Wilhelm, J.C. Piacentini, ..., J.W. Mink Current controversies on the role of behavior therapy in Tourette syndrome Movement Disorders, 28 (2013), pp. 1179-1183, 10.1002/mds.25488

Silverman and Albano, 1996 W.K. Silverman, A.M. Albano The Anxiety Disorders Interview Schedule for DSM-IV, Child Version: Clinician manual Oxford University Press, New York, NY (1996)

Silverman et al., 2001 W.K. Silverman, L.M. Saavedra, A.A. Pina Test-retest reliability of anxiety symptoms and diagnoses with the Anxiety Disorders Interview Schedule for DSM-IV: Child and Parent Versions Journal of the American Academy of Child and Adolescent Psychiatry, 40 (2001), pp. 937-944, 10.1097/00004583-200108000-00016

Singer, 2011 H.S. Singer Tourette syndrome and other tic disorders Handbook of Clinical Neurology, 100 (2011), pp. 641-657, 10.1016/b978-0-444-52014-2.00046-x

Specht et al., 2011 M.W. Specht, D.W. Woods, J. Piacentini, L. Scahill, S. Wilhelm, A.L. Peterson, ..., J.T. Walkup Clinical characteristics of children and adolescents with a primary tic disorder Journal of Developmental and Physical Disabilities, 23 (2011), pp. 15-31, 10.1007/s10882-010-9223-z

Speed, 1996 J. Speed Behavioral management of conversion disorder: Retrospective study Archives of Physical Medicine and Rehabilitation, 77 (2) (1996), pp. 147-154

Storch et al., 2007 E.A. Storch, C.W. Lack, L.E. Simons, W.K. Goodman, T.K. Murphy, G.R. Geffken A measure of functional impairment in youth with Tourette's syndrome Journal of Pediatric Psychology, 32 (2007), pp. 950-959, 10.1093/ipepsy/ism034

Storch et al., 2005 E.A. Storch, T.K. Murphy, G.R. Geffken, M. Sajid, P. Allen, J.W. Roberti, W.K. Goodman Reliability and validity of the Yale Global Tic Severity Scale Psychological Assessment, 17 (2005), pp. 486-491, 10.1037/1040-3590.17.4.486

Sukhodolsky et al., 2003 D. Sukhodolsky, L. Scahill, H. Zhang, B.S. Peterson, R.A. King, P.J. Lombroso, ..., J.F. Leckman Disruptive behavior in children with Tourette's syndrome: Association with ADHD comorbidity, tic severity, and functional impairment Journal of the American Academy of Child and Adolescent Psychiatry, 42 (2003), pp. 98-105, 10.1097/00004583-200301000-00016

Tryon, 2008 W.W. Tryon Whatever happened to symptom substitution? Clinical Psychology Review, 28 (2008), pp. 963-968, 10.1016/i.cpr.2008.02.003

Walkup et al., 1992 J.T. Walkup, L.A. Rosenberg, J. Brown, H.S. Singer The validity of instruments measuring tic severity in Tourette's syndrome Journal of the American Academy of Child and Adolescent Psychiatry, 31 (1992), pp. 472-477, 10.1097/00004583-199205000-00013

Wilhelm et al., 2003 S. Wilhelm, T. Deckersbach, B.J. Coffey, A. Bohne, A.L. Peterson, L. Baer Habit reversal versus supportive psychotherapy for Tourette's disorder: A randomized controlled trial American Journal of Psychiatry, 160 (2003), pp. 1175-1177, 10.1176/appi.ajp.160.6.1175

Wilhelm et al., 2012 S. Wilhelm, A.L. Peterson, J. Piacentini, D.W. Woods, T. Deckersbach, D.G. Sukhodolsky, ..., L. Scahill Randomized trial of behavior therapy for adults with Tourette syndrome Archives of General Psychiatry, 69 (2012), pp. 795-803, 10.1001/archgenpsychiatry.2011.1528

Behavior Therapy, Vol. 47, No. 1 (January 2016): pg. 29-41. DOI. This article is (C) Elsevier and permission has been granted for this version to appear in e-Publications@Marquette. Elsevier does not grant permission for this article to be further copied/distributed or hosted elsewhere without the express permission from Elsevier. 
Wille, 1993 S. Wille Primary nocturnal enuresis in children. Background and treatment Scandinavian Journal of Urology and Nephrology: Supplementum, 156 (1993), pp. 1-48

Wille and Anveden, 1995 S. Wille, I. Anveden Social and behavioural perspectives in enuretics, former enuretics and non-enuretic controls Acta Paediatrica, 84 (1) (1995), pp. 37-40

Wood et al., 2002 J. Wood, J. Piacentini, R. Bergman, J. McCracken, V. Barrios Concurrent validity of the anxiety disorders section of the Anxiety Disorders Interview Schedule for DSM-IV: Child and Parent Versions Journal of Clinical Child and Adolescent Psychology, 31 (2002), pp. 335-342, $10.1207 / 153744202760082595$

Woods et al., 2007 D.W. Woods, C.A. Conelea, M.R. Walther Barriers to dissemination: Exploring the criticisms of behavior therapy for tics Clinical Psychology: Science and Practice, 14 (2007), pp. 279-282, 10.1111/j.1468-2850.2007.00088.x

Woods et al., 2008 D.W. Woods, J.C. Piacentini, S. Chang, T. Deckersbach, G.S. Ginsburg, A.L. Peterson, ..., S. Wilhelm Managing Tourette syndrome: A behavioral intervention for children and adults Oxford University Press, New York, NY (2008)

Woods et al., 2011 D.W. Woods, J.C. Piacentini, L. Scahill, A.L. Peterson, S. Wilhelm, S. Chang, ..., J.T. Walkup Behavior therapy for tics in children: Acute and long-term effects on psychiatric and psychosocial functioning Journal of Child Neurology, 26 (2011), pp. 858-865, $\underline{10.1177 / 0883073810397046}$

Woods et al., 2003 D.W. Woods, M.P. Twohig, C.A. Flessner, T.J. Roloff Treatment of vocal tics in children with Tourette syndrome: Investigating the efficacy of habit reversal Journal of Applied Behavior Analysis, 36 (2003), pp. 109-112, 10.1901/jaba.2003.36-109

Behavior Therapy, Vol. 47, No. 1 (January 2016): pg. 29-41. DOI. This article is (C) Elsevier and permission has been granted for this version to appear in e-Publications@Marquette. Elsevier does not grant permission for this article to be further copied/distributed or hosted elsewhere without the express permission from Elsevier. 